\title{
Extruded bread classification on the basis of acoustic emission signal with application of artificial neural networks
}

\author{
Izabela Świetlicka ${ }^{*}$, Siemowit Muszyński ${ }^{1}$, and Agata Marzec ${ }^{2}$ \\ ${ }^{1}$ Department of Physics, University of Life Sciences, Akademicka 13, 20-950 Lublin, Poland, \\ ${ }^{2}$ Department of Food Engineering and Process Management, Warsaw University of Life Sciences (SGGW), \\ Nowoursynowska 159c, 02-776 Warszawa, Poland \\ Received December 3, 2013; accepted January 30, 2015
}

\begin{abstract}
A b s t r a c t. The presented work covers the problem of developing a method of extruded bread classification with the application of artificial neural networks. Extruded flat graham, corn, and rye breads differening in water activity were used. The breads were subjected to the compression test with simultaneous registration of acoustic signal. The amplitude-time records were analyzed both in time and frequency domains. Acoustic emission signal parameters: single energy, counts, amplitude, and duration acoustic emission were determined for the breads in four water activities: initial ( 0.362 for rye, 0.377 for corn, and 0.371 for graham bread), 0.432, 0.529, and 0.648. For classification and the clustering process, radial basis function, and self-organizing maps (Kohonen network) were used. Artificial neural networks were examined with respect to their ability to classify or to cluster samples according to the bread type, water activity value, and both of them. The best examination results were achieved by the radial basis function network in classification according to water activity (88\%), while the self-organizing maps network yielded $81 \%$ during bread type clustering.

K e y w o r d s: extruded bread, acoustic emission, artificial neural networks, classification, clustering
\end{abstract}

\section{INTRODUCTION}

Acoustic emission analysis is an important aspect of food texture evaluation, as particular sound obtained during food crushing could convey a lot of information about final product acceptability. The group of food products whose quality is assessed on the basis of the sound emitted when biting is represented by products such as bread, crisps, chips, and some fruits and vegetables.

The importance of sound in food quality evaluation was first recognized by Drake $(1963,1965)$, who showed that sounds emitted during food breaking differ from each other

*Corresponding author e-mail: izabela.swietlicka@up.lublin.pl by amplitude, frequency, and pitch and suggested that sound and vibrations accompanying mastication could be used to complement food sensory analysis (Dacremont, 1995). Vickers and Bourne (1976) concluded that during biting crispy food generates specific sounds of a sharp, short, and noisy type. Spectral analysis of these sounds revealed that the investigated signal included components within a $0-10 \mathrm{kHz}$ frequency band, which suggested a hypothesis that the perceived crispness level is proportional to the signal amplitude registered by the instrumentation. Vickers and Wasserman (1979) attempted to verify the assumption that the sound of crushed product includes a pattern specific to the tested sample structure.

Many recent studies (Marzec et al., 2007b; Ono and Huang, 1994; Zdunek et al., 2011a) have shown that novel acoustic emission (AE) techniques could bring a pattern recognition tool in the field of non-destructive food evaluation. Tests carried out both in the case of dry (Duizer, 2001; Marzec et al., 2007a, 2007b) and wet (Zdunek et al., 2010a, $2010 \mathrm{~b}$ ) farm and food products indicate that, depending on storage conditions, changes in mechanical parameters of food products could be noticed by changes in AE signal. What is more, differences in the signal for the same product type but different varieties, such as rye bread and wheat bread are perceived (Marzec et al., 2007b).

Amplitude of acoustic waves (Drake, 1965), mean height of peaks or number of sound bursts (Edmister and Vickers, 1985), acoustic energy (AlChakra et al., 1996) mean sound pressure or acoustic intensity (Seymour and Hamann, 1988) are the most popular acoustic parameters commonly used as a measure of food crispness or crunchiness.

(C) 2015 Institute of Agrophysics, Polish Academy of Sciences 
Another method of AE signal analysis is also application of AE descriptors such as AE counts, AE events, or AE energy (Marzec et al., 2007b, Zdunek et al., 2010a, 2011a).

The effect of water activity on acoustic properties of crunchy food was also widely studied (Dacremont, 1995; Primo-Martin et al., 2009). Measurements have shown that the intensity of emitted sound was strongly related to the material moistness as changes in AE signal for extruded flat bread along with moisture modifications were observed (Marzec et al., 2007b). The correlations between emitted sound and their turgor pressure as well as the storage temperature were also observed (Zdunek et al., 2008).

The results mentioned above showing the relationship between AE signal and mechanical properties of crunchy food indicate that there might be an interest in developing automatic, objective algorithms to support the process of predicting the quality of crisp products and identifying their type or properties on the basis of AE signal parameters using non-classical mathematical and statistical methods.

Artificial neural networks (ANN) are widely used in the field of signal classification (Aslan et al., 2008; Bishop, 1995; Gelzinis et al., 2008; Yang et al., 2009). ANN, unlike traditional statistical methods, adjusts to data without the necessity of defining any additional function or distribution of input variables. They are also able to determine the probability of object membership in a group, which brings the possibility of using ANN as a kind of a posteriori probability estimators (Hung et al., 1996; Isa et al., 2009; Kline and Berardi, 2005). It is known that ANN are capable of mapping the probability distribution even when a limited number of learning cases is applied (Hung et al., 1996). The ANN method started to be used also in the area of AE signal analysis as a tool to determine the usefulness of the sound signal features as predictors of sensory crispness, identification of wood species, and quality assessment (Godin et al., 2004; Pearson et al., 2007). Many a time ANN turned out to be more efficient than eg PCA mainly due to the fact that they are allotted to describe complex, multidimensional, and nonlinear relationships, presenting results in a form of low-dimensional geometrical relations and are able to customize to presented data (ANN are characterized by high flexibility both in the learning and architecture aspects).
The aim of the presented work was to cluster and classify extruded flat breads on the basis of AE signal determinants with the use of artificial neural networks. Selected radial basis function networks (RBF) and self-organizing maps (SOM, Kohonen networks) were tested and evaluated in respect of their ability to recognize and classify acoustic samples according to bread types and/or their water activity values.

\section{MATERIALS AND METHODS}

Commercial extruded flat bread slices purchased in local store were used in this work. The basic physical parameters of the slices are presented in Table 1. Initial water activity $\left(\mathrm{a}_{\mathrm{wi}}\right)$ of the specimens was measured using Hygorometer 3 (Rotronic, Switzerland) with an accuracy of $+/-0.001$ of $\mathrm{a}_{\mathrm{w}}$ unit at a temperature of $25^{\circ} \mathrm{C}$; it amounted to 0.362 for rye, 0.377 for corn, and 0.371 for graham bread. Prior to the measurements, the apparatus was calibrated using saturated salt solutions of $\mathrm{NaCl}$ and $\mathrm{LiCl}$.

Extruded flat bread slices taken directly from the retail packages were equilibrated to various water activities over saturated salt solutions in desiccators for 10 weeks at $25^{\circ} \mathrm{C}$. Three analytical grade salts were used: potassium carbonate $\mathrm{K}_{2} \mathrm{CO}_{3}\left(\mathrm{a}_{\mathrm{w} 4}=0.432\right)$, magnesium nitrate $\mathrm{Mg}\left(\mathrm{NO}_{3}\right)_{2}$ $\left(\mathrm{a}_{\mathrm{w} 5}=0.529\right)$, and sodium nitrite $\mathrm{NaNO}_{2}\left(\mathrm{a}_{\mathrm{w} 6}=0.648\right)$.

Thymol crystals were placed inside the desiccators in order to prevent any bacterial spoilage of the samples or fungal activity.

20 slices of extruded flat bread for each examined $a_{w}$ were subjected to the compression test performed with a Zwick 1445 loading machine equipped with an accelerometric piezoelectric sensor Bruel and Kjaer $4381 \mathrm{~V}$ mounted between the moving head of the machine and the testing probe. As the AE sensor was fixed directly to the testing probe (compression plate), the direct acoustic contact (mechanical vibrations) with the examined samples was assured. The sensor was not registering stray vibrations conducted by the air. The compression test was performed for two non-overlapping fragments of each bread sample.

The compression plate was an aluminium cylinder probe with a radius $\varnothing 35 \mathrm{~mm}$. Loading was performed at the constant crosshead speed of $10 \mathrm{~mm} \mathrm{~min}^{-1}$, and the AE sensor was registering the acoustic signal at the frequency

T a b l e 1. Physical properties of extruded flat bread

\begin{tabular}{|c|c|c|c|c|c|}
\hline \multirow{2}{*}{ Bread type } & \multicolumn{3}{|c|}{ Dimension (mm) } & \multirow{2}{*}{ Mass (g) } & \multirow{2}{*}{$\begin{array}{c}\text { Initial water } \\
\text { activity }\end{array}$} \\
\hline & height & width & thickness & & \\
\hline Rye & $117.6 \pm 1.4$ & $52.5 \pm 2.4$ & $8.19 \pm 0.14$ & $7.88 \pm 0.18$ & $0.362 \pm 0.002$ \\
\hline Corn & $121.8 \pm 0.3$ & $53.0 \pm 0.6$ & $7.96 \pm 0.43$ & $7.39 \pm 0.80$ & $0.377 \pm 0.004$ \\
\hline Graham & $116.3 \pm 1.2$ & $51.9 \pm 0.5$ & $8.12 \pm 0.08$ & $7.32 \pm 0.56$ & $0.371 \pm 0.006$ \\
\hline
\end{tabular}


T a b 1 e 2. Sample distribution $\left(a_{w i}, a_{w 4}, a_{w 5}\right.$ and $a_{w 6}-$ water activities)

\begin{tabular}{|c|c|c|c|c|c|}
\hline \multirow{2}{*}{$\begin{array}{l}\text { Bread } \\
\text { type }\end{array}$} & \multicolumn{4}{|c|}{ Water activities } & \multirow{2}{*}{$\Sigma$} \\
\hline & $\mathrm{a}_{\mathrm{wi}}$ & $\mathrm{a}_{\mathrm{w} 4}$ & $\mathrm{a}_{\mathrm{w} 5}$ & $\mathrm{a}_{\mathrm{w6}}$ & \\
\hline Corn & 28 & 36 & 30 & 30 & 124 \\
\hline Graham & 32 & 16 & 32 & 32 & 112 \\
\hline Rye & 32 & 37 & 30 & 30 & 129 \\
\hline$\Sigma$ & 92 & 89 & 92 & 92 & 365 \\
\hline
\end{tabular}

range of $0.1 \div 15 \mathrm{kHz}$. The AE signal was transmitted form the sensor to a $20 \mathrm{~dB}$ low-noise amplifier and registered using a $44.1 \mathrm{kHz}$ sampling sound card mounted in a PC computer. Program WaveSound 5 (Creative Labs., USA) was used to register the final AE signal.

As the result of the measurement, a set of 16-37 sound samples for each bread type was obtained. Although AE was recorded for $15 \mathrm{~s}$, only the first $10 \mathrm{~s}$ were subjected to the analysis. Finally, $36510 \mathrm{~s}$ samples of the AE signal were obtained (Table 2). Four different parameters characterising $\mathrm{AE}$ events were determined: single $\mathrm{AE}$ energy $(\mathrm{mJ}), \mathrm{AE}$ counts, $\mathrm{AE}$ amplitude $(\mathrm{mV})$, and $\mathrm{AE}$ duration $(\mu \mathrm{s})$ defined as (Marzec et al., 2007b) using PC applications for sound analysis (Lewicki et al., 2009). The parameters were determined for each bread type in four different water activities: initial $\mathrm{a}_{\mathrm{wi}}$, amounting to 0.362 for rye, 0.377 for corn, and 0.371 for graham bread, $0.432,0.529$, and 0.648 labelled as $\mathrm{a}_{\mathrm{w} 4}, \mathrm{a}_{\mathrm{w} 5}$, and $\mathrm{a}_{\mathrm{w} 6}$, respectively. The discrimination level was set on $1000 \mathrm{mV}$. Each amplitude transition above the discrimination level was recorded as a count of the $\mathrm{AE}$, while the time interval that contained the group of the AE signal of a damped sinusoid character was recognized as the AE count.

The data obtained were analyzed according to their ability to differentiate among three groups: in respect of water activity (experiment 1 ), bread type (experiment 2 ), and taking into consideration both water activity and bread type (experiment 3). The STATISTICA 10.0 application was used for the statistical calculations.

The correlation coefficients (Table 3) demonstrated no statistically important linear relation among variables, which leads to the conclusion that AE parameters are not simply connected with the bread type or water activity values. Additionally, the dispersion figures (Fig. 1) proved that the calculated AE descriptors vary within the groups. In order to verify the above-mentioned observation, descriptive statistics and cross-sectional analysis for the calculated determinants were performed.

The differences in the mean values calculated with the use of the Welch test proved that the groups differed significantly according to dependent variable means. However,
T a b l e 3. Correlation coefficients determined for accoustic emission (AE) parameters in relation to dependent variables

\begin{tabular}{lccc}
\hline $\begin{array}{l}\text { Accoustic } \\
\text { emission }\end{array}$ & Bread type & Water activity & $\begin{array}{c}\text { Bread type } \\
\text { and water } \\
\text { activity }\end{array}$ \\
\hline Single energy & -0.41 & 0.09 & -0.36 \\
Counts & -0.36 & -0.35 & -0.46 \\
Amplitude & -0.59 & -0.06 & -0.58 \\
Duration & -0.12 & 0.14 & -0.07 \\
\hline
\end{tabular}
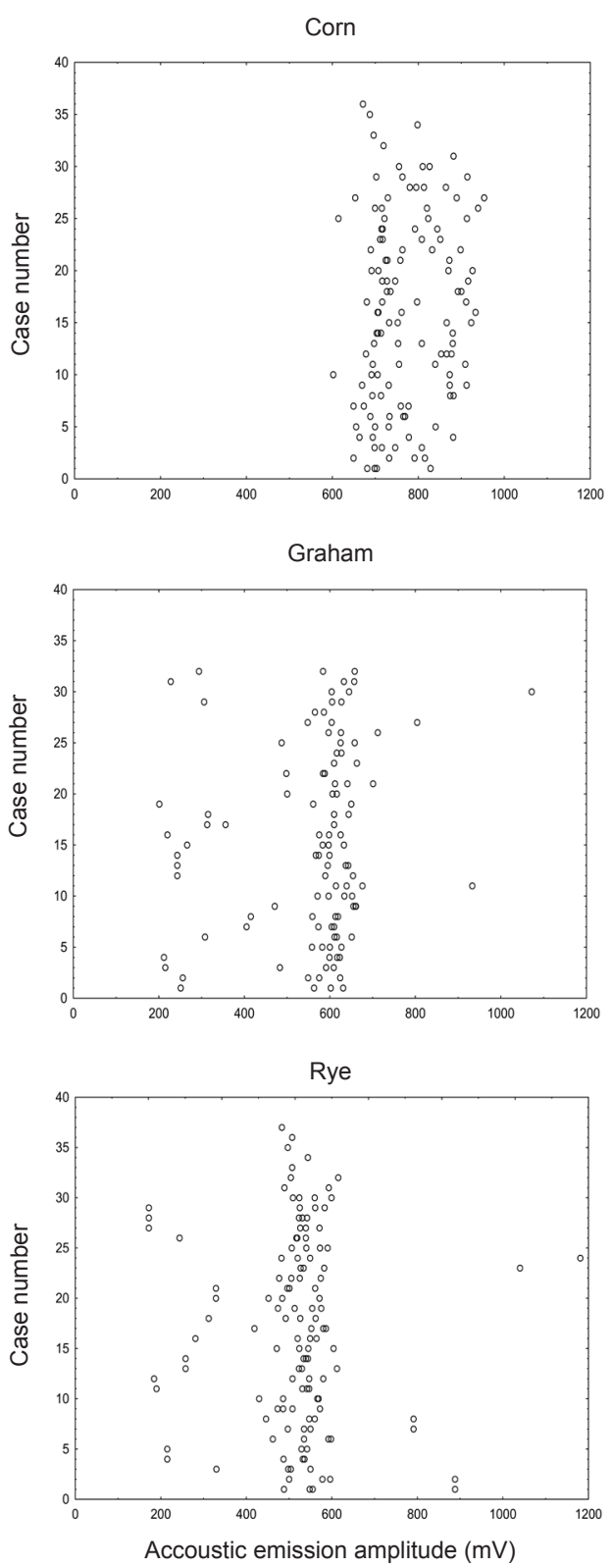

Fig. 1. Dispersion figures for the AE amplitude according to the bread type. 
T a b l e 4. Kruskal-Wallis ANOVA values according to calculated determinants

\begin{tabular}{|c|c|c|c|c|c|c|}
\hline \multirow{3}{*}{ Parameter } & \multicolumn{6}{|c|}{ Experiment } \\
\hline & \multicolumn{2}{|c|}{1 - water activity } & \multicolumn{2}{|c|}{2 - bread type } & \multicolumn{2}{|c|}{3 - water activity and bread type } \\
\hline & $\mathrm{H}$ & $\mathrm{p}$ & $\mathrm{H}$ & $\mathrm{p}$ & $\mathrm{H}$ & $\mathrm{p}$ \\
\hline Single AE energy & 10.2 & 0.0167 & 210.5 & 0.0000 & 237.8 & 0.0000 \\
\hline AE counts & 230.7 & 0.0000 & 33.9 & 0.0000 & 297.0 & 0.0000 \\
\hline AE amplitude & 9.3 & 0.0259 & 221.2 & 0.0000 & 247.7 & 0.0000 \\
\hline AE duration & 99.1 & 0.0000 & 130.1 & 0.0000 & 232.8 & 0.0000 \\
\hline
\end{tabular}

Effects are significant with $\mathrm{p}<0.05 . \mathrm{H}-$ Kruskal-Wallis test value.

Levene test as well as the robust test of means equality (Brown-Forsythe) showed that the homogeneity of variances was not saved, which leads to the conclusion that data should be analyzed using non-parametric methods. Accordingly, Kruskal-Wallis ANOVA (Table 4), which is an alternative to ANOVA for data that are not characterized by variance homogeneity, was used in order to check if the groups differed in respect of the calculated variables. The Kruskal-Wallis test value $(\mathrm{H})$ values and high significance of the statistic test $(p<0.05)$ indicate that the determined variables made a significant contribution to the differentiation of the groups and provided a basis for classifier construction.

Variables describing three bread types in all the examined water activities were firstly standardized according to Eq. (1):

$$
z_{i j}=\frac{x_{i j}-\bar{x}}{\sigma},
$$

where: $z_{i j}$ - new variable element, $x_{i j}$ - original variable element, $\bar{x}-$ a mean of original variable, $\sigma$ - original variable standard deviation. The chart was next randomly divided into three groups - teaching, verifying, and testing, and then introduced to the network input. For each experiment type, a separate network classifier was designed. The influence of the structure and learning parameters on the network working abilities was checked. The number of inputs was determined by the number of independent variables and amounted to 4 . The number of hidden layers and neurons in each of them RBF or the neuron number in the output layer SOM were established in an experimental way, using the growth method taking into consideration the validation error (Castellano et al., 1997; Karnin, 1990). The acceptance and rejection thresholds amounted to 0.95 and 0.05 , respectively, which corresponded to the standard classification with a $95 \%$ confidence level.

The tested RBF networks were built with one hidden layer and, depending on the classification problem with 4 (experiment 1), 3 (experiment 2), or 12 (experiment 3 ) outputs. The basis function centres were subjected to update with the k-means algorithm application, while the basis functions radius $\sigma$ was established using a k-NN algorithm. In the output layer, normalizing logistic function was applied, which allowed using the conjugate gradient (CG) as an optimization algorithm, since then the outputs could be interpreted as the probability of object membership in the class (Yang et al., 2009). The mean-squared error (MSE) was applied as an error.

The tested Kohonen networks were of rectangular shape with the output layer formed by $9,16,25,36,49,64$, or 81 radial neurons. As recommended (Cottrell et al., 1998; Mulier and Cherkassky, 1995; Song and Hopke, 1996), a twophase learning algorithm was applied. The first learning phase (rough learning) was characterized by a strongly decreasing learning rate and neighbourhood that allowed general mapping with large groups of neurons responding to similar data (Kohonen, 2001). In the second stage (stabilizing), the network was trained significantly longer and constant and low values of the neighbourhood range and learning rate $\alpha$ were established. Training started with random values of weights. The networks were taught during 100 epochs in the first and 1000 in the second stage. The learning rate decreased from 0.7 to 0.1 in the first stage, while during second phase it was fixed at 0.1 . The neighbourhood range declined from the maximum value for the analyzed network to 1 , while in the second phase its value was set at 0 . This approach allowed adjustment of topological maps in a way that enabled individual neurons to respond to small clusters built with related input cases; thereby SOM neurons were able to create a certain similarity class among the input data.

The selected classifiers were assessed with the classification accuracy $(a c c)$ (Eq. (2)) and overall error rate $(\varepsilon)$ determined on the basis of a testing set (Eq. (3)):

$$
\begin{gathered}
a c c=N_{c} / N_{t}, \\
\varepsilon=1-a c c,
\end{gathered}
$$

where: $N_{c}$ - correctly classified cases from the testing set, $\mathrm{N}_{t}-$ the number of all testing cases. 
The error made by the networks in the validation process $($ vacc) was an additional measure used in classifier evaluation. The validation set used simultaneously with the teaching data acts as a cross-validation test - comparison of the network in terms of prediction capability for the validation data ie comparison of classification accuracy rates. It should be pointed out that in the case of the Kohonen network the error is expressed as the distance between the nearest input pattern and its centre, and therefore the network errors differ in terms of dimension. Additionally, for the SOM networks, the topological maps (two-dimensional image of the output layer) were also subjected to the analysis. The map quality evaluation was carried out on the basis of the number of dead neurons (DN) - neurons, which never won for a given data set and are located outside neurons forming the cluster (Lee and Verleysen, 2002).

\section{RESULTS AND DISSCUSION}

A vast number of studies have been published with a view to characterizing and predicting the effects of water activity on food crispness and related acoustic properties (Saeleaw and Scheleining, 2011). The study of the acoustic properties of extruded bread and other crispy foods in relation to its water content is complex because these properties are affected by several extra factors in addition to the fracture properties of the crispy food surface, as pore size for example (Primo Marin et al., 2009; Salvador et al., 2009). Nevertheless, it is generally accepted that the number of acoustic events is strongly affected by the water activity and increasing aw causes a decrease in the number of acoustic events (Gondek et al., 2006; Primo-Martin et al., 2009). As the number of sound events is correlated nega- tively with the water content, a range of analyzed water activities was selected to ensure maintenance of crispiness of the extruded bread (Marzec et al., 2007b).

The present study is aimed to show the ability of ANN models to classify extruded flat bread stored in different experimental conditions on the basis of the acoustic emission descriptors. The two approaches shown were based on self-organizing maps (SOM) and a multilayer perceptron (MLP). These two networks are known for their clustering (SOM) and classification capabilities (MLP) despite the fact that they have different learning strategy. The comparison of the two models and their topologies was based on selected statistical indices. The results obtained are discussed in detail below.

To the best of our knowledge, no data have been published about application of ANN for instrumental characterization of the acoustic emission descriptors for not only crispy breads, but any food products, and we are unable to relate our results to the studies of other researchers.

Table 5 shows teaching, validation, and testing rates as well as errors for each of the data groups depending on the number of neurons in the output layer (RBF) and output neurons (SOM). It is known that an increase in the number of output neurons/neurons in the hidden layer causes an increase in teaching, validation, and testing rates but to a certain point, after which the values mentioned begin to fall.

Simultaneously, the error values decrease to the minimum and start to grow after crossing the optimal parameters. This is connected with overlearning - the network over-fits the learning points, which is accompanied by unstable behaviour for data not presented during the learning (the network does not have the ability to generalize).

T a b l e 5. Teaching, validation, and testing rates and errors for chosen RFB and SOM networks

\begin{tabular}{|c|c|c|c|c|c|c|c|}
\hline \multirow{2}{*}{$\begin{array}{l}\text { Network } \\
\text { type }\end{array}$} & \multirow{2}{*}{$\begin{array}{l}\text { Neurons in hidden } \\
\text { layer /Number of } \\
\text { output neurons }\end{array}$} & \multicolumn{3}{|c|}{ Rate } & \multicolumn{3}{|c|}{ Error } \\
\hline & & teaching & validation & testing & teaching & validation & testing \\
\hline \multicolumn{8}{|c|}{ Experiment 1 (water activity) } \\
\hline $\mathrm{RBF}$ & 35 & 0.90 & 0.86 & 0.88 & 0.20 & 0.25 & 0.24 \\
\hline SOM & 16 & 0.78 & 0.70 & 0.77 & 1191 & 1514 & 1763 \\
\hline \multicolumn{8}{|c|}{ Experiment 2 (bread type) } \\
\hline $\mathrm{RBF}$ & 23 & 0.88 & 0.85 & 0.87 & 0.26 & 0.26 & 0.41 \\
\hline SOM & 25 & 0.84 & 0.84 & 0.81 & 667 & 709 & 683 \\
\hline \multicolumn{8}{|c|}{ Experiment 3 (water activity and bread type) } \\
\hline $\mathrm{RBF}$ & 55 & 0.92 & 0.78 & 0.67 & 0.13 & 0.18 & 0.18 \\
\hline SOM & 25 & 0.54 & 0.48 & 0.52 & 1000 & 1110 & 1166 \\
\hline
\end{tabular}


Due to that fact, networks with maximum teaching, validation, and testing rates and minimum error values were considered as optimal.

The main purpose of designing a classifier was to obtain a tool that would allow fast and reliable identification of previously unknown data. Artificial neural networks applied in the area of classification on the basis of the AE signal determinants were assessed in respect of their ability to recognize and classify bread samples according to water activity values (experiment 1), bread type (experiment 2 ), or both of them (experiment 3 ).

The best recognition rates $(a c c)$ were achieved for the RBF classifier, which was able to correctly identify $88 \%$ from data that had not been presented previously. SOM achieved recognition rates at a level of $77 \%$.
Validation accuracy (vacc), which is regarded as a test if the network has high generalizing skills, reached a level of 86 and $70 \%$ for RBF and SOM, respectively (Table 6).

On the basis of the results obtained, it could be concluded that for both the RBF and SOM networks the group with $\mathrm{a}_{\mathrm{w} 6}$ was the easiest to be recognized (Table 7).

The topological map (Fig. 2) designed for SOM shows that neurons corresponding to water activity values are arranged in a manner allowing linear separation of regions responsible for particular water activity.

The recognition rates (acc) amounted to $87 \%$ for the RBF classifier and $81 \%$ for the SOM network. Rye bread proved to be the most complicated to be classified in both cases (Table 6).

T a b I e 6. Classification statistics for the RBF and SOM networks while classifying according to water activity values (experiment 1), bread types (experiment 2), and both of them (experiment 3)

\begin{tabular}{|c|c|c|c|c|c|c|c|c|c|c|c|c|}
\hline \multirow{2}{*}{ Network } & \multicolumn{4}{|c|}{$\begin{array}{l}\text { Experiment } 1 \\
\text { (water activity) }\end{array}$} & \multicolumn{4}{|c|}{$\begin{array}{l}\text { Experiment } 2 \\
\text { (bread type) }\end{array}$} & \multicolumn{4}{|c|}{$\begin{array}{c}\text { Experiment } 3 \\
\text { (water activity and bread type) }\end{array}$} \\
\hline & $a c c(\%)$ & $\varepsilon(\%)$ & $\begin{array}{c}v a c c \\
(\%)\end{array}$ & $\begin{array}{l}\text { verror/ } \\
\text { DN }\end{array}$ & $a c c(\%)$ & $\varepsilon(\%)$ & $\begin{array}{l}\text { vacc } \\
(\%)\end{array}$ & $\begin{array}{l}\text { verror/ } \\
\text { DN }\end{array}$ & $a c c(\%)$ & $\varepsilon(\%)$ & $\begin{array}{l}\text { vacc } \\
(\%)\end{array}$ & $\begin{array}{l}\text { verror/ } \\
\text { DN }\end{array}$ \\
\hline $\mathrm{RBF}$ & 88 & 12 & 86 & 0.25 & 87 & 13 & 85 & 0.26 & 77 & 23 & 70 & 0.2 \\
\hline SOM & 77 & 23 & 70 & 0 & 81 & 19 & 84 & 2 & 52 & 48 & 48 & 1 \\
\hline
\end{tabular}

T a b I e 7. Classification statistics for the RBF and SOM networks while classifying according to water activity values (experiment 1), bread types (experiment 2), and both of them (experiment 3 ) and classification correctness in the examined groups calculated for the testing set $\left(\mathrm{a}_{\mathrm{wi}}, \mathrm{a}_{\mathrm{w} 4}, \mathrm{a}_{\mathrm{w} 5}\right.$ and $\mathrm{a}_{\mathrm{w} 6}-$ water activities)

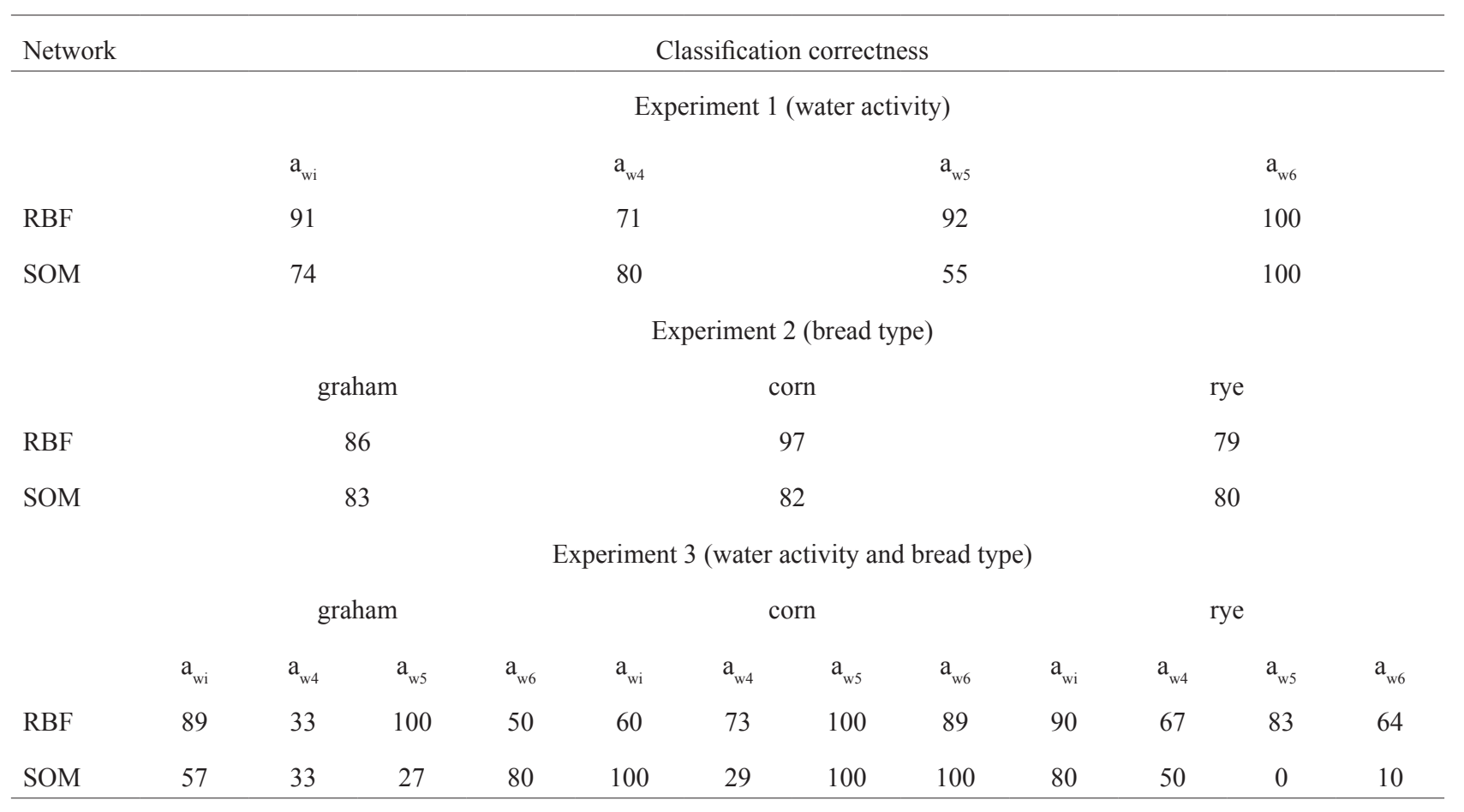




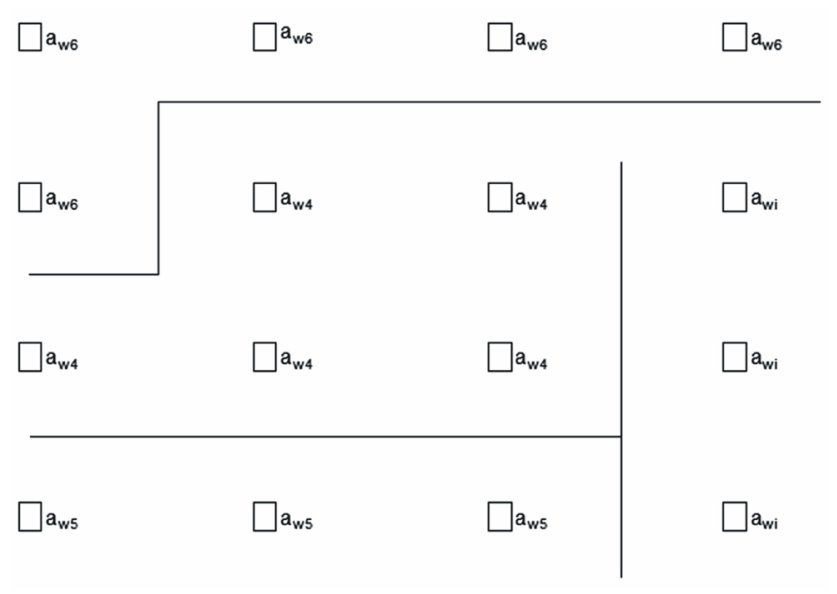

Fig. 2. Topological map for clustering according to the water activity $\left(\mathrm{a}_{\mathrm{wi}}, \mathrm{a}_{\mathrm{w} 4}, \mathrm{a}_{\mathrm{w} 5}, \mathrm{a}_{\mathrm{w} 6}-\right.$ water activity values).

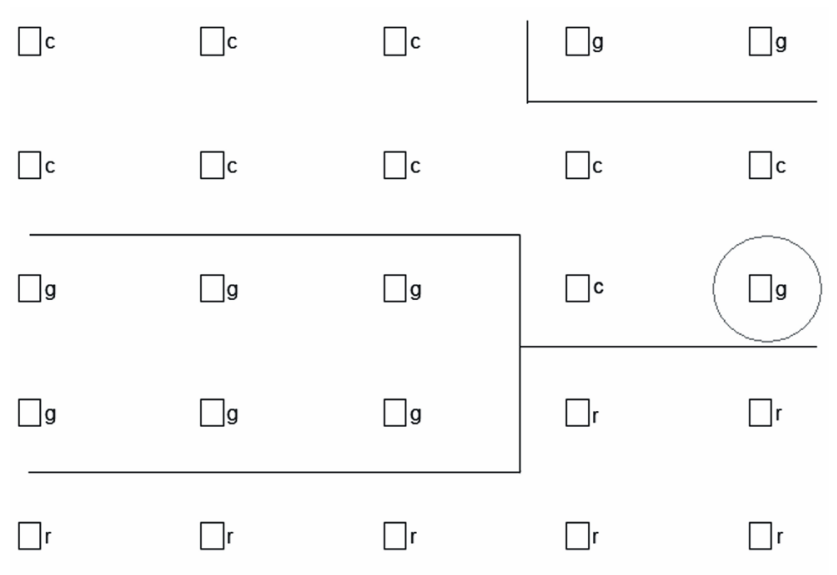

Fig. 3. Topological map for bread type clustering (c-corn, g-graham, r-rye). The circled neuron was labelled as responsible for graham; however, it was placed in the corn cluster.

As mentioned above, the number of dead neurons (DN) was used for evaluation of the Kohonen network. Table 6 shows that the DN value in experiment 2 reached 2, which corresponds to $8 \%$ of the network resources (for a network with 25 output neurons in total) and has no effect on the network working abilities. The topological map (Fig. 3) is not as clear as in experiment 1 , but regions assigned to particular bread types could also be distinguished. Only one neuron was not labelled properly - a single neuron responsible for the graham group was located in the corn bread area (Fig. 3 marked with a circle).

For experiment 3 , the values of the recognition rates decreased significantly to $77 \%$ for RBF and only $52 \%$ for SOM, which means that the SOM network was not able to accomplish the task with satisfactory results (Table 6). The highest correctness was achieved for samples that had $\mathrm{a}_{\mathrm{w} 5}$ or

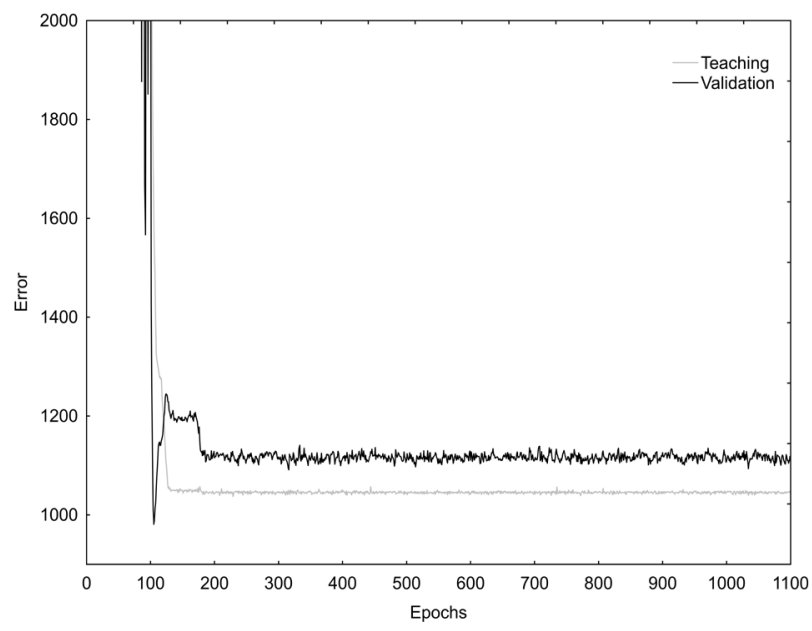

Fig. 4. SOM training graph for teaching and validation data set used in experiment 3 (clustering in respect of water activity and bread type).

$\mathrm{a}_{\mathrm{w} 6}$ and were derived from corn bread. The validation accuracy for the SOM network reached only $48 \%$, which points to a conclusion that the network was not taught properly.

The training graph shows that, during validation, the network was not able to stabilize the error level (Fig. 4); therefore, it did not adapt correctly to the input data. The most probable cause of that was the insufficient number of teaching cases compared to the solved issue. The network was supposed to differentiate 12 groups based on the 120 teaching and 120 validation cases, which apparently was not enough to realize the clustering process with satisfactory results. Due to the fact that SOM achieved unsatisfactory results, only the RBF classifier was subjected to the analysis.

On basis of the results presented in the confusion matrix (Table 8), it could be concluded that the wrongly recognized samples were incorrectly classified only in terms of one parameter: bread type (c, g, r) or water activity $\left(a_{w i}, a_{w 4}\right.$, $\mathrm{a}_{\mathrm{w} 5}$ and $\mathrm{a}_{\mathrm{w} 6}$ ), while 2 of them were incorrectly classified in relation to both of analyzed factors $-\mathrm{ca}_{\mathrm{w} 4}$ as $_{\mathrm{ga}} \mathrm{w}_{\mathrm{w}}$ and $\mathrm{ra}_{\mathrm{w} 5}$ as $\mathrm{ga}_{\mathrm{wi}}$ (Table 7 on the light grey background).

The results presented above indicate that one or more of $\mathrm{AE}$ determinants were characteristic for another group.

In order to verify the parameters of significance during the classification process, sensitivity analysis was performed (Table 9). The basic measure of the network sensitivity was the error ratio obtained for the data set without a single variable and the error obtained with a complete set of variables. The greater the error after the variable rejection was the more sensitive to the lack of this variable the network was. A ratio close to or less than one indicates that the rejection of the variable has no effect or improves the network quality. The conducted analysis revealed that the $\mathrm{AE}$ count parameter was the most crucial determinant for all the three classifiers. 
T a b l e 8. Confusion matrix considering activities and bread types for the RBF classifier $\left(c-c o r n, g-g r a h a m, r-r y e, a_{w i}, a_{w 4}, a_{w 5}\right.$ and $\mathrm{a}_{\mathrm{w} 6}-$ water activities)

\begin{tabular}{lcccccccccccc}
\hline $\begin{array}{l}\text { Breads and } \\
\text { water activity } \\
\text { groups }\end{array}$ & $\mathrm{ca}_{\mathrm{wi}}$ & $\mathrm{ca}_{\mathrm{w} 4}$ & $\mathrm{ca}_{\mathrm{w} 5}$ & $\mathrm{ca}_{\mathrm{w} 6}$ & $\mathrm{ga}_{\mathrm{wi}}$ & $\mathrm{ga}_{\mathrm{w} 4}$ & $\mathrm{ga}_{\mathrm{w} 5}$ & $\mathrm{ga}_{\mathrm{w} 6}$ & $\mathrm{ra}_{\mathrm{wi}}$ & $\mathrm{ra}_{\mathrm{w} 4}$ & $\mathrm{ra}_{\mathrm{w} 5}$ & $\mathrm{ra}_{\mathrm{w} 6}$ \\
\hline $\mathrm{ca}_{\mathrm{wi}}$ & 3 & 0 & 0 & 0 & 0 & 0 & 0 & 0 & 0 & 0 & 0 & 0 \\
$\mathrm{ca}_{\mathrm{w} 4}$ & 2 & 7 & 0 & 1 & 0 & 0 & 0 & 0 & 0 & 0 & 0 & 0 \\
$\mathrm{ca}_{\mathrm{w} 5}$ & 0 & 1 & 7 & 0 & 0 & 0 & 0 & 0 & 0 & 0 & 0 & 0 \\
$\mathrm{ca}_{\mathrm{w} 6}$ & 0 & 2 & 0 & 7 & 0 & 0 & 0 & 0 & 0 & 0 & 0 & 1 \\
$\mathrm{ga}_{\mathrm{wi}}$ & 0 & 0 & 0 & 0 & 7 & 0 & 0 & 0 & 3 & 0 & 1 & 0 \\
$\mathrm{ga}_{\mathrm{w} 4}$ & 0 & 0 & 0 & 0 & 0 & 1 & 0 & 0 & 0 & 0 & 0 & 0 \\
$\mathrm{ga}_{\mathrm{w} 5}$ & 0 & 1 & 0 & 0 & 1 & 0 & 6 & 0 & 0 & 0 & 0 & 0 \\
$\mathrm{ga}_{\mathrm{w} 6}$ & 0 & 0 & 0 & 0 & 1 & 0 & 0 & 4 & 0 & 0 & 0 & 5 \\
$\mathrm{ra}_{\mathrm{wi}}$ & 0 & 0 & 0 & 0 & 0 & 0 & 0 & 0 & 7 & 0 & 0 & 0 \\
$\mathrm{ra}_{\mathrm{w} 4}$ & 0 & 0 & 0 & 0 & 0 & 2 & 0 & 0 & 0 & 3 & 0 & 1 \\
$\mathrm{ra}_{\mathrm{w} 5}$ & 0 & 0 & 0 & 0 & 0 & 0 & 0 & 0 & 0 & 3 & 5 & 0 \\
$\mathrm{ra}_{\mathrm{w} 6}$ & 0 & 0 & 0 & 1 & 0 & 0 & 0 & 4 & 0 & 0 & 0 & 4 \\
\hline
\end{tabular}

T a b l e 9. Significance of accoustic emission (AE) descriptors in the classification process for the RBF classifier. Ranks show importance of variables in accordance with the ratio value

\begin{tabular}{lccccc}
\hline Experiment & Descriptor & $\begin{array}{c}\text { Single AE energy } \\
(\mathrm{mJ})\end{array}$ & AE counts & $\begin{array}{c}\text { AE amplitude } \\
(\mathrm{mV})\end{array}$ & $\begin{array}{c}\text { AE duration } \\
(\mu \mathrm{s})\end{array}$ \\
\hline $\begin{array}{l}1 \\
\text { (water activity) }\end{array}$ & Ratio & 1.144 & 1.982 & 1.685 & 1.279 \\
2 & Rank & 4 & 1 & 2 & 3 \\
(bread type) & Ratio & 1.107 & 1.253 & 1.244 & 0.697 \\
3 (water activity & Rank & 3 & 1 & 2 & 4 \\
and bread type) & Ratio & 1.076 & 4.128 & 1.632 & 1.041 \\
\hline
\end{tabular}

\section{CONCLUSIONS}

1. The performed test proved that acoustic emission signal processing allows determination of useful parameters, on the basis of which clustering and classification of farm and food products could be conducted.

2. The determined parameters of accoustic emission: single energy, counts, amplitude, and duration proved to be key variables while clustering or classifying food samples on the basis of the accoustic emission signal; however the number of accoustic emission counts was the most important.
3. The number of accoustic emission counts influenced the classification process to the highest degree and had the greatest contribution to the differentiation of the groups along with accoustic emission amplitude, which was indicated to be the second most important.

4. The artificial neural networks applied in the classification process correctly recognised over $70 \%$ of samples although they were not able to classify samples according to both the bread type and water activity value. However, in our opinion, classification of bread according only to water activity is much more important than to the bread type since the bread type is usually easier to control. 
5. The results obtained have shown that artificial neural networks might be applied in the area of farm and food products classification as well as recognition of their physical properties on the basis of accoustic emission signal parameters.

\section{REFERENCES}

AlChakra W., Allaf K., and Jemai A.B., 1996. Characterization of brittle food products: application of the acoustical emission method. J. Texture Studies, 27, 327-348.

Aslan K., Bozdemir H., Şahin C., Oğulata S.N., and Erol R., 2008. A radial basis function neural network model for classification of epilepsy using EEG signals. J. Medical Systems, 32, 403-408.

Bishop C.M., 1995. Neural networks for pattern recognition, Oxford University Press.

Castellano G., Fanelli A., and Pelillo M., 1997. An iterative pruning algorithm for feedforward neural networks, IEEE Trans. Neural Networks, 8, 519-531.

Cottrell M., Fort J.C., and Pages G., 1998. Theoretical aspects of the SOM algorithm. Neurocomputing, 21, 119-138.

Dacremont C., 1995. Spectral Composition of Eating Sounds Generated by Crispy Crunchy and Crackly Foods. J. Texture Studies, 26, 27-43.

Drake B.K., 1963. Food crushing sounds. An introductory study. J. Food Sci., 28, 233-241.

Drake B.K., 1965. Food crushing sounds: comparisons of objective and subjective data. J. Food Sci., 30, 556-559.

Duizer L., 2001. A review of acoustic research for studying the sensory perception of crisp, crunchy and crackly textures. Trends Food Sci. Technol., 12, 17-24.

Edmister J.A. and Vickers Z.M., 1985. Instrumental acoustical measures of crispness in foods. J. Texture Studies, 16, 153-167.

Gelzinis A., Verikas A., and Bacauskiene M., 2008. Automated speech analysis applied to laryngeal disease categorization, Computer Methods Programs Biomedicine, 91, 36-47.

Godin N., Huguet S., Gaertner R., and Salmon L., 2004. Clustering of acoustic emission signals collected during tensile tests on unidirectional glass/polyester composite using supervised and unsupervised classifiers. NDT\&E International, 37, 253-264.

Gondek E., Lewicki P.P., and Ranachowski Z., 2006. Influence of water activity on the acoustic properties of breakfast cereals. J. Texture Studies, 37(5), 497-515.

Hung M.S., Hu M.Y., Shanker M.S., and Patuwo B.E., 1996. Estimating posterior probabilities in classification problems with neural networks. Int. J. Computational Intelligence Organizations, 1(1), 49-60.

Isa D., Kallimani V.P., and Lee L.H., 2009. Using the self organizing map for clustering of text documents. Expert Systems Applications, 96, 9584-9591.

Karnin E.D., 1990. A simple procedure for pruning back-propagation trained neural networks. IEEE Trans. Neural Networks, 1(2), 239-242.

Kline D.M. and Berardi V.L., 2005. Revisiting squared-error and cross-entropy functions for training neural network classifiers. Neural Computing Appl., 15, 310-318.

Kohonen T., 2001. Self-Organizing Maps, Springer, Berlin.

Lee J.A. and Verleysen M., 2002. Self-organizing maps with recursive neighbourhood adaptation. Neural Networks, 15, 993-1003.
Lewicki P.P., Marzec A., and Ranachowski Z., 2009. Acoustic properties of foods. In: Food Properties Handbook (Ed. M.S. Rahman). CRC Press, Boca Raton, FL, USA.

Marzec A., Lewicki P.P., and Pietrowska A., 2007a. Staling of bread evaluation with application of acoustical method (in Polish). Food Sci. Technol. Quality, 2(51), 72-79.

Marzec A., Lewicki P.P., and Ranachowski Z., 2007b. Influence of water activity on acoustic emission of flat extruded bread. J. Food Eng., 79, 410-422.

Mulier F.M. and Cherkassky V.S., 1995. Statistical analysis of self-organization. Neural Networks, 8(5), 717-727.

Ono K. and Huang Q., 1994. Pattern recognition analysis of acoustic emission signals. Progress in Acoustic Emission. Japanese Soc. NDI, 7, 69-78.

Pearson T.C., Eniscetin A., Tewfik A.H., and Haff R.P., 2007. Feasibility of impact acoustic emissions for detection of damaged wheat kernels. Digital Signal Proc., 17, 617-633.

Primo-Martín C., Sözer N., Hamer R.J., and Vliet T.V., 2009. Effect of water activity on racture and acoustic characteristics of a crust model. J. Food Eng., 90(2), 277-284.

Saeleaw M. and Schleining G., 2011. A review: Crispness in dry foods and quality measurements based on acoustic-mechanical destructive techniques. J. Food Eng., 105, 387-399.

Salvador A., Varela P., Sanz T., and Fiszman S.M., 2009. Understanding potato chips crispy texture by simultaneous fracture and acoustic measurements, and sensory analysis, LWT - Food Science and Technol., 42(3), 763-767.

Seymour S.K. and Hamann D.D., 1988. Crispness and crunchiness of selected low moisture foods. J. Texture Studies, 19, 79-95.

Song X.-H. and Hopke P.K., 1996. Kohonen neural network as a pattern recognition metod based on weight interpretation. Analytica Chimica Acta, 334, 57-66.

Vickers Z.M. and Bourne M.C., 1976. Crispness in foods - a review. J. Food Sci., 41, 153-157.

Vickers Z.M. and Wasserman S.S., 1979. Sensory qualities of food sounds based on individual perceptions. J. Texture Studies, 10, 319-332.

Yang P., Zhu Q., and Zhong X., 2009. Subtractive clustering based RBF neural network model for outlier detection. J. Computers, 4(8), 755-762.

ZdunekA., Frankevych L., Konstankiewicz K., and Ranachowski Z., 2008. Comparision of puncture test, acoustic emission and spatial-temporal speckle correlation technique as method foe apple quality evaluation. Acta Agrophysica, 11(1), 303-315.

Zdunek A., Cybulska J., Konopacka D., and Rutkowski K., 2010a. New contact acoustic emission detector for texture evaluation of apples. J. Food Eng., 99, 83-91.

Zdunek A., Konopacka D., and Jesionkowska K., 2010 b. Crispness and crunchiness judgment of apples based on contact acoustic emission. J. Texture Studies, 41,75-91.

Zdunek A., Cybulska J., Konopacka D., and Rutkowski K., 2011a. Inter-laboratory analysis of firmness and sensory texture of stored apples. Int. Agrophysics, 25, 67-75.

Zdunek A., Cybulska J., Konopacka D., and Rutkowski K., 2011 b. Evaluation of apple texture with contact acoustic emission detector: A study on performance of calibration models. J. Food Eng., 106(1), 80-87. 